\title{
Gene Expression Patterns of Geese Expression Patterns of L-Fabp, Spot 14, Ob and Apo A1 Genes in Different Tissues of Overfed and Control Geese
}

\section{-Author(s)}

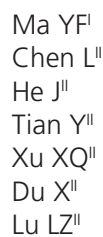

Jinhua Polytechnic, No. 1188, Wuzhou Street., Jinhua, Zhejiang, 321000, China Institute of Animal Husbandry and Veterinary Science, Zhejiang Academy of Agricultural Sciences, No. 145, Shiqiao Road, Hangzhou, Zhejiang, 310021, China

\section{Mail Address}

Corresponding author e-mail address L. Z. Lu

Institute of Animal Husbandry and Veterinary Science, Zhejiang Academy of Agricultural

Sciences, No. 145, Shiqiao Road,

Hangzhou, Zhejiang, 310021, China.

Tel: $\quad+86057186404214$

Email: lulizhibox@163.com

\section{-Keywords}

Langde goose, lipids related genes, gene expression, fatty liver.

\section{ABSTRACT}

Ten-week-old Langde geese in similar body weight were randomly selected, four for overfeeding and four for routinly feeding. The abundance of liver fatty acid-binding protein (L-FABP), thyroid hormoneresponsive (THRSP or Spot 14), obese $(O B)$, and apolipoprotein $A 1$ (Apo A1) genes in goose were detected by quantitative RT-PCR. L-FABP was higher expressed in liver and intestine than other tissues, but no expression was detected in the pancreas or brain. The other three genes were widely expressed in different tissues, $O B$ was higher expressed in pancreas and abdominal fat, Spot 14 and Apo A1 was higher expressed in sebum and abdominal fat. Spot 14 and Apo A1 genes were upregulated in overfed goose livers compared with that in the control. Thus, Spot 14 and Apo A1 genes may play important roles in lipid metabolism in goose fat liver.

\section{INTRODUCTION}

Fatty acid-binding proteins (FABPs) play important roles in the transport of fatty acids from the plasma membrane to the sites of $\beta$ oxidation or/and triacylglycerol or phospholipid synthesis (Veerkamp et al., 1995). FABPs are members of the intracellular lipid-binding protein family. Among the 12 known FABPs (Liu et al., 2008), the liver-type FABP (L-FABP) was the first to be cloned from recombinant resources. The $L-F A B P$ gene was highly expressed in the liver, and $L-F A B P$ gene-knock-down rats had significantly lower transportation of fatty acids compared with the control (Wang et al., 2006). The thyroid hormone-responsive (THRSP or Spot 14) gene was determined to be highly expressed in the liver of chicken and also expressed in fat tissues (Wang et al., 2002). Spot 14 expression was associated with the expression of the thyroid hormone (Wang et al., 2002). In human lipid metabolism, Spot 14 was proved to participate in the regulation of the transcription of six enzymes, namely, malic enzyme, ATP-citrate lyase, fatty acid synthase, pyruvate kinase, phosphoenolpyruvate carboxy kinase, and acetyl-CoA carboxylase (Brown et al., 1997). Apolipoprotein A1 (Apo A1) is the main activating factor of lecithin cholesterol acyltransferase and plays the key role in reverse cholesterol transportation. Apo A1 gene expression was detected and associated with the level of high-density lipoprotein cholesterol (HDLC) (Vega et al., 2001). Leptin is the product of obese $(O B)$ gene. Leptin could suppress appetite, increase energy consumption, and reduce fat content in mice (Pelleymounter et al., 1995; Halaas et al., 1995). Lipid metabolisms in mammal and chicken have been reported clearly, but not in goose.

This study was performed to elucidate the lipid metabolism in goose. We selected several important genes related to lipid metabolism, 
namely, L-FABP, Spot 14, $A p o A 1$, and $O B$ genes. We detected the expression patterns of these genes in different tissues and determined their differences between control and overfed (OF) geese.

\section{MATERIALS AND METHODS}

\section{Sample collection}

Ten-week-old Langde geese were randomly assigned into control group (C) and overfed group (OF), each group contain four geese. $C$ geese were fed with basal diet and OF geese were fed with basal diet mixed with $0.4 \%$ goose fat and $0.1 \%$ salt. The overfeeding period lasted for 20 days after a period of 1 week of pre-overfeeding. Quantitative real-time PCR analysis was applied to detect mRNA abundance and differential expression patterns of the $L-F A B P$, Spot 14,OB, and Apo $A 1$ genes in the different tissues of $C$ and OF geese. Fourteen tissues (heart, liver, spleen, lung, kidney, brain, chest muscle, leg muscle, sebum, abdominal fat, intestine, proventriculus, gizzard, and pancreas) were collected from each individual. The tissues were immediately frozen in liquid nitrogen and stored at $-70{ }^{\circ} \mathrm{C}$ for total RNA extraction. The geese were slaughtered following ethical standards.

This study was carried out in strict accordance with the recommendations in the Guide for the Care and Use of Laboratory Animals of the National Institutes of Health. All surgery was performed according to recommendations proposed by European Commission, and all efforts were made to minimize suffering of animals.

\section{Total RNA extraction and reverse trans- cription}

Trizol regent (Takara, Osaka, Japan) was used to isolate the total RNA, and M-MLV reverse transcriptase (Takara) was used to synthesize the complementary
DNA. Aforementioned processes were performed according to the manufacturer's protocols.

\section{Quantitative RT-PCR}

Primers used in this study are listed in Table 1. Quantitative RT-PCR analysis was performed in 20 $\mu \mathrm{L}$ of reaction mixture, which included $2 \mu \mathrm{L}$ of $\mathrm{CDNA}$ template, $10 \mu \mathrm{L}$ of $2 \times$ SYBR qPCR mix, $0.4 \mu \mathrm{M}$ forward/reverse primer, and $0.4 \mu \mathrm{L}$ of ROX reference dye (Takara). The reaction was performed on $A B I$ 7300 (Applied Biosystems, Foster City, CA) using the following protocol: $94{ }^{\circ} \mathrm{C}$ for $3 \mathrm{~min}, 40$ cycles of denaturation at $94{ }^{\circ} \mathrm{C}$ for $10 \mathrm{~s}$, and annealing and extension at $60{ }^{\circ} \mathrm{C}$ for $31 \mathrm{~s}$. Each detection was performed thrice simultaneously.

\section{Statistical analysis}

Relative expression levels of goose $L-F A B P$, Spot 14, $A$ po $A 1$, and $O B$ genes were indicated by $2^{-\Delta C t}$, where $\Delta C t=C t_{\text {target gene }}-C_{\text {GAPDH }}$. Statistical significance was calculated using the Student's $t$-test with 2-tailed $p$-values (SPSS version 16.0). Differences were considered significant when $p<0.05$. Tests were performed among tissues and between treatments.

\section{RESULTS}

\section{Expression patterns of L-FABP, Spot 14, $O B$, and Apo A1 genes in goose}

The expression patterns of goose L-FABP, Spot 14, $O B$, and $A p o A 1$ genes in the different tissues are shown in Fig. 1. L-FABP gene was found to be highly expressed in the liver and intestine and also expressed in various tissues. No L-FABP expression was detected in the pancreas or brain. Spot 14 gene was highly expressed in all tissues, especially in the fat tissues and intestine. $O B$ gene was expressed in all tissues. Apo A1 gene was highly expressed in the fat tissues, intestine, and liver, compared with those in the other tissues.

Table 1 - Sequences of primers used in this study.

\begin{tabular}{|c|c|c|c|c|}
\hline \multirow[b]{2}{*}{ Primer } & \multicolumn{2}{|c|}{ Nucleotide sequence $\left(5^{\prime} \rightarrow 3^{\prime}\right)$} & \multirow[b]{2}{*}{ Accession no. } & \multirow[b]{2}{*}{ Size } \\
\hline & Sense & Antisense & & \\
\hline $\mathrm{L}-\mathrm{FABP}^{1}$ & actgcccccactgcgtt & cgtcaccacaaagtcgtctcct & HQ640427 & 184 \\
\hline Spot 14 & tgcgtgtgtctaaaccacct & tcgaggctttgcgttttatt & GW713791 & 83 \\
\hline Apo $\mathrm{A} 1^{2}$ & aacttgcgcgagaagatgac & aagcgggtcttgaggttctc & NM_205525 & 83 \\
\hline $\mathrm{OB}^{2}$ & gacttcattcctgggcttca & ccaggtcatcggctatctgt & AF082500 & 124 \\
\hline GAPDH & gtggtgctaagcgtgtca & aggctgggataatgttctgg & AY436595 & 290 \\
\hline
\end{tabular}

${ }^{1}$ Referenced the sequences in duck

${ }^{2}$ Referenced the sequences in chicken 
Ma YF, Chen L, He J, Tian Y, Xu XQ, Du X, Lu LZ
Gene Expression Patterns of Geese Expression

Patterns of L-Fabp, Spot 14, Ob and Apo A1 Genes in Different Tissues of Overfed and Control Geese

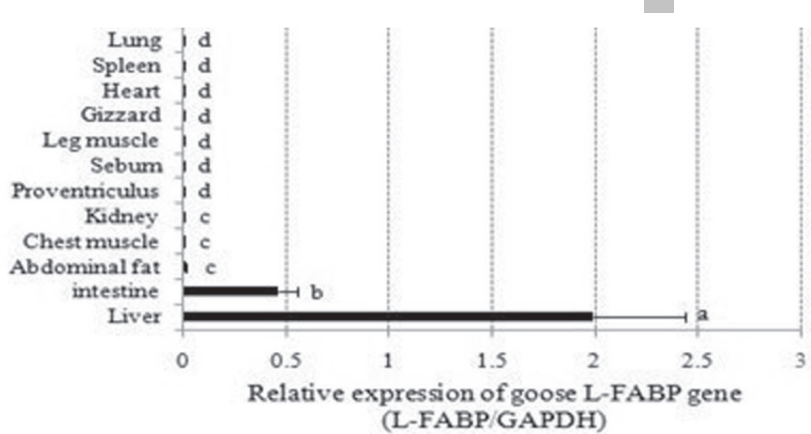

(L-FABP/GAPDH)
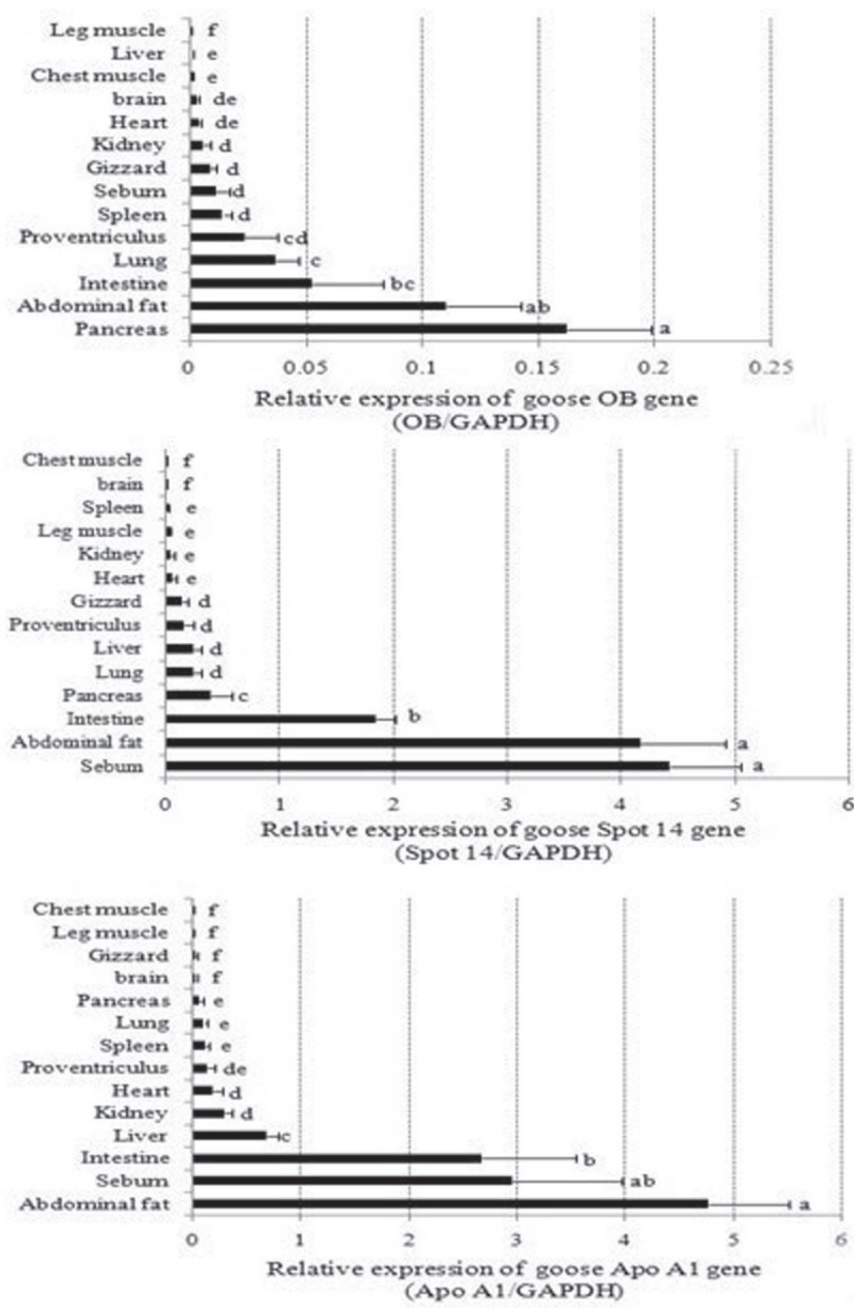

Figure 1 - Expression patterns of liver fatty acid-binding protein (L-FABP), thyroid hormone-responsive (THRSP or Spot 14), obese (OB), and apolipoprotein A1 (Apo A1) genes in goose.

Expression levels of these genes in the different tissues were determined by quantitative RT-PCR and normalized to that of GAPDH. No L-FABP gene was detected in the pancreas or brain. Each column in each diagram represents the mean \pm SEM of four individuals. This condition applies to the following diagram. Different letters indicate significant difference at $p<0.05$.

\section{Differential expression in control and OF geese}

Significant higher expression of Spot 14 and Apo A1 genes was detected in OF goose livers, compared with those of the control $(p<0.05)$ (Fig. 2). No significant difference was detected in other tissues $(P>0.05)$. No differential expression in the goose $L-F A B P$ or $O B$ gene was detected $(p>0.05)$

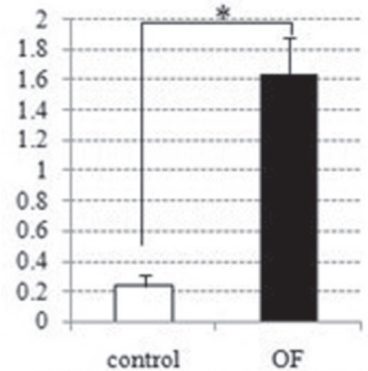

Relative expression of Spot 14 gene (Spot 14/GAPDH)

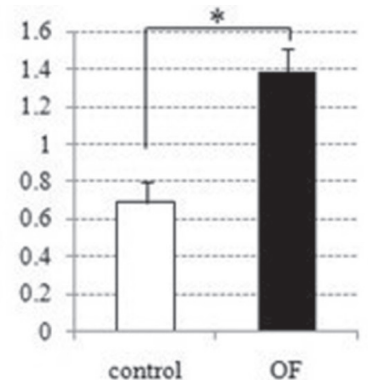

Relative expression of Apo Al gene (Apo A1/GAPDH)
Figure 2 - Differential expression levels of Spot 14 and Apo A1 genes.

Expression levels of Spot 14 and Apo A1 genes in overfed (OF) geese were significantly higher than those in the control group $(p<0.05)$.

\section{DISCUSSION}

Goose fat liver is one of the three most famous cuisines worldwide. This study was primarily performed to investigate several lipid metabolism-related genes in goose and their differential expression patterns between OF geese and control. Goose L-FABP gene was detected to be highly expressed in the liver and intestine, similar to the reports of Besnard et al. (2002) and Guilmeau et al. (2007). No L-FABP expression was detected in the pancreas or brain. Goose Spot 14 gene was found to be highly expressed in the fat tissues, intestine, lung, and liver, which is consistent to those in human and rat (Jump et al., 1993). The OB gene was reported to be highly expressed in the fat and intestine, which is consistent with the results in Fig. 1. Goose Apo A1 gene was also found to be highly expressed in the fat tissues, intestine, and liver, which are important organs for lipid metabolism. These lipid metabolism-related genes were all detected to widely exist in different tissues in goose.

Quantitative RT-PCR analysis showed that Spot 14 and Apo A1 genes were expressed higher in OF goose livers than those in the control (Fig. 2). The liver is a very important organ for lipid metabolism in vivo. These results indicated that lipid metabolism was more active in OF geese than control. Spot 14 was proved to regulate the transcriptions of six key enzymes in lipid metabolism (Brown et al., 1997), and Spot 14 protein was indispensable in fat synthesis (Oppenheimer et al., 1987). Apo A1 functions in reverse cholesterol transportation (Vega et al., 2001). Apo A1 is part of high-density lipoprotein (HDL), and HDLC was negatively associated with incidence of coronary atherosclerosis disease (Vega et al., 1996). The results 
Ma YF, Chen L, He J, Tian Y, Xu XQ, Du X, Lu LZ
Gene Expression Patterns of Geese Expression Patterns of L-Fabp, Spot 14, Ob and Apo A1 Genes in Different Tissues of Overfed and Control Geese of Apo A1 gene in this study might indicate that goose fat liver was healthier for human. Otherwise, the regulations of these genes in goose liver remain ambiguous.

In conclusion, the expression patterns of goose $L-F A B P$, Spot 14,OB, and Apo $A 1$ genes in various tissues were detected. Differential expression analysis showed that the expression levels of Spot 14 and Apo A1 genes in OF goose livers were significantly higher than those in the control.

\section{ACKNOWLEDGEMENTS}

This work was supported by the Significant Project of Science and Technology of Zhejiang Province, P. R. China (No. 2007C 14023) and National 948 Projects, China (No. 2012-Z47).

\section{REFERENCES}

Besmond LC, Aggerbeck LP, Bado A, Samson-Bouma ME. Decreased expression of Intestinal I- and L-FABP levels in rare human genetic lipid malabsorption syndromes. Histochemistry and Cell Biology 2007:128:115-123.

Besnard P, Niot I, Poirier H, Clément L, Bernard A. New insights into the fatty acid-binding protein (FABP) family in the small intestine. Molecular and Cellular Biochemistry 2002;239:139-147.

Brown SB, Maloney M, Kinlaw WB. "Spot 14" protein functions the pretranslational level in regulation of hepatic metabolism by thyroid hormone and glucose. Journal of Biological Chemistry 1997;272 (4):2163-2166
Guilmeau S, Niot I, Laigneau JP, Devaud $H$, Petit $V$, Brousse $N$, et al. Polyunsaturated fatty acids inhibit S14 gene transcription in rat liver and cultured hepatocytes. Proceeding of the National Academy of Sciences 1993;90:8454-8458.

Liu RZ, Li XD, Godbout R. A novel fatty acid-binding protein (FABP) gene resulting from tandem gene duplication in mammals: transcription in rat retina and testis. Genomics 2008;92(6):436-445.

Oppenheimer JH, Kinlaw WB, Wong NC, Schwartz HL, Mariash CN. Regulation of gene S-14 by triiodothyronine in liver. Hormone and Metabolic Research 1987;17:1-5.

Pelleymounter MA, Cullen MJ, Baker MB, Hecht R, Winters D, Boone T, et al. Weight-reducing effects of the plasma protein encoded by the obese gene. Science 1995;269:543-546.

Pelleymounter MA, Cullen MJ, Baker MB, Hecht R. Effects of the obese gene product on body weight regulation on ob/ob mice. Science 1995;269:540-543.

Veerkamp JH, Maatman RG. Cytoplasmic fatty acid-binding proteins:their structure and genes. Progress in Lipid Research 1995;34(1):17-52.

Vega GL, Grundy SM. Hypoalphalipoproteinemia as a risk factor for coronary heart disease. Current Oppinion in Lipidology 2001;7:209-216.

Wang Q, Li H, Li N, Leng L, Wang Y. Tissue expression and association with fatness traits of liver fatty acid-binding protein gene in chicken. Poultry Science 2006;85(11):1890-1895.

Wang X, Carre W, Rejto L, Cogburn LA. Global gene expression profiling in liver of thyroid manipulated and or growth hormone injected broiler chickens. Poultry Science 2002;81(Suppl 1):63. 